\title{
Updates in the Guidelines and Treatment of Ventilator-dependent Children
}

\author{
An Expert Interview with Ronald L Morton \\ University of Louisville School of Medicine, Louisville, KY, US
}

DOI: https://doi.org/10.17925/USRPD.2018.13.1.19

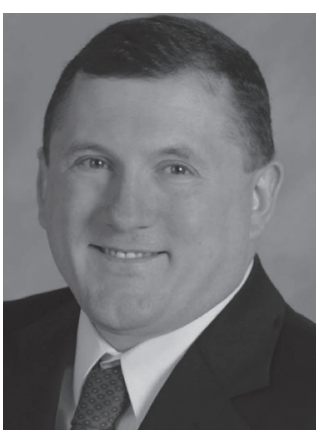

\section{Ronald L Morton}

Ronald L Morton, MD, earned his medical degree at the University of Illinois College of Medicine in Chicago. He completed his pediatric internship and residency at the William Beaumont Army Medical Center in El Paso, Texas. His pediatric fellowship was completed at the University of Colorado Medical Center in Denver, Colorado and National Jewish Research Center. Dr Morton served as staff pediatrician for 4 years and as chief of the Pediatric Clinic for 2 years at the Lyster US Army Hospital at Fort Rucker, Alabama. Dr Morton is now Professor of Pediatrics at the University of Louisville School of Medicine and is a staff physician at Norton Children's Hospital. He is Director of the Cystic Fibrosis Center, and Director of the Ventilator Unit at the Pediatric Convalescent Center. Home of the Innocents. In 2005, Dr Morton received the Northeastern Ohio Universities College of Medicine Excellence in Research Award and the University of Louisville School of Medicine Graduating Resident Class of 2005 Child Advocacy Award. In 2006, he received the University of Louisville School of Medicine Leonard Tow Humanism in Medicine Award presented by the Arnold P Gold Foundation. He is a member of the American Thoracic Society, American College of Chest Physicians, and American Academy of Pediatrics. Dr Morton has presented his research at many national meetings and has published over 70 articles and abstracts relating to pulmonary disease, asthma and cystic fibrosis.

\section{Keywords}

Chronic home invasive ventilation, ventilator-dependent children, ATS guidelines

Disclosure: Ronald L Morton has no conflicts of interest to disclose in relation to this article.

Review Process: This is an expert interview and, as such, has not undergone the journal's standard peer review process.

Authorship: The named author meets the International Committee of Medical Journal Editors (ICMJE) criteria for authorship of this manuscript, takes responsibility for the integrity of the work as a whole, and has given final approval for the version to be published.

open Access: This article is published under the Creative Commons Attribution Non-commercial License, which permits any non-commercial use, distribution, adaptation, and reproduction provided the original author and source are given appropriate credit. (c) The Author 2018.

Received: August 10, 2018

Published Online: September 17, 2018

Citation: US Respiratory \& Pulmonary

Diseases. 2018;3(1):19-21

Corresponding Author: Ronald L Morton,

University of Louisville, 571 S Floyd, Suite 414, Louisville, KY 40202, US. E: ron.morton@|ouisville.edu

Support: No funding was received in

the publication of this article.
$\mathrm{M}$ experience in the care of ventilator-dependent children involves over 20 years' experience in both the home and long-term care environments. I have managed over 50 ventilator-dependent children in a university-based practice and have weaned at least two children per year completely off mechanical ventilation. In addition, I have helped in the development of a ventilator dependent unit in the only exclusive pediatric long-term care facility in the State of Kentucky (Home of the Innocents, Louisville, KY), where we currently have 13 ventilator-dependent children.

In January 2016, the American Thoracic Society published consensus guidelines regarding several questions centered around the care of children requiring chronic home invasive mechanical ventilation. ${ }^{1}$ In April 2017, the Canadian Thoracic Society published clinical practice guidelines on pediatric home mechanical ventilation, with a disease specific focus on conditions associated with the need for long-term ventilation. ${ }^{2}$ In this brief synopsis, I will attempt to summarize some of the critical questions addressed in these two recommendations, which affect long-term home ventilation in the pediatric population.

\section{Q. What are the major challenges facing the families of children requiring chronic home invasive ventilation?}

The major challenges facing families of children requiring chronic home invasive ventilation are the lack of adequate home nursing support, the inadequate number of primary care providers willing to provide a "medical home" for these highly complex children, and the complexity in navigating the complex web of community resources. The current guidelines recommend, "that at least two specifically trained family caregivers are prepared to care for the child in the home." These caregivers can be two trained family caregivers or a combination of professional and family caregivers. While the guidelines do not explicitly say that a professional caregiver (i.e., registered nurse/licensed practical nurse) is required, certain situations (i.e., extremely premature infants with many complex medical needs including home mechanical ventilation) mandate that a professional caregiver assist the family in the care of their child on home mechanical ventilation. One drawback of this approach of requiring a professional caregiver in the home is the lack of home nursing support in many areas, especially 
rural areas of the country. The lack of home nursing support oftentimes delays the discharge of these infants from the neonatal intensive care unit for many months. In spite of this challenge, the most important aspect in the care of these children involves having awake, attentive and adequately trained caregivers in the home.

A second challenge for these families centers around the lack of a medical home or primary care provider willing to manage the long-term needs of the child on home invasive mechanical ventilation. The medical home concept, developed by the American Academy of Pediatrics over 10 years ago, ensures that highly medically complex children receive care that is "accessible, continuous, comprehensive, family-centered, coordinated, compassionate, and culturally effective. ${ }^{13}$ The primary care provider remains an essential component of the care team of the home ventilator-dependent child, especially acting as a gatekeeper in coordinating the many sub-specialists that these children often need.

\section{Q. What factors influence the decision to discharge from hospital children requiring chronic invasive ventilation?}

The factors that influence the decision to discharge from the hospital children requiring chronic invasive ventilation include "(1) the child's medical stability for discharge, (2) the preparedness of family and professional home caregivers, (3) the necessary medical equipment, and (4) the safety of the home and community environment."1

A period of medical stability involves stability of the respiratory system, ventilator requirements and other medical conditions. A stable respiratory system includes a stable/secure airway (i.e., a tracheostomy in the ventilator-dependent child), able to clear and suction secretions, stable respiratory compliance and resistance, and stable oxygen requirements (preferably fraction of inspired oxygen $\left[\mathrm{FiO}_{2}\right]<0.5-0.6$ and positive end expiratory pressures [PEEP] $<8-10 \mathrm{~cm} \mathrm{H}_{2} \mathrm{O}$ ). We usually require a period of respiratory stability for a minimum of $2-3$ weeks prior to transfer out of the intensive care unit. In addition, other medical systems that may affect the respiratory system (i.e., cardiac, renal, or neurologic dysfunction) must be well controlled prior to discharge from the hospital.

The guidelines for home care of the ventilator-dependent child also recommend adequate community and home resources. A durable medical equipment (DME) provider must be identified that can provide support and provide a 24-hour service for the family and child on mechanical ventilation. Some of the tasks that the respiratory therapist (RT) and DME providers may be called upon to perform include (1) troubleshooting alarms, (2) assisting in adjusting the ventilator settings during the weaning process, (3) replacing equipment that malfunctions, (4) home visitations on a monthly basis, including sending ventilator downloads to the pulmonary physician. The guidelines recommend that a back-up ventilator be available in the home in case of equipment failure. Other community resources that must be in place include notification of the local emergency medical services and emergency departments of a plan for transport of the ventilator-dependent child, and notification of the electrical company in case of power failure. The home must be inspected prior to discharge to ensure adequate safety, including electrical outlets, fire extinguisher, constant ambient temperature and humidity, and a smoke-free zone.

\section{Q. What training and support is available in the US for the parents of children requiring chronic home invasive ventilation?}

The training and support available in the US for parents of children requiring chronic home invasive ventilation is one component of a comprehensive discharge planning process. The hospital must maintain standardized discharge planning protocols to assess readiness for discharge to a lower level of care (home or long-term care facility). These standardized operating procedures provide the basic outline for the training that all family members taking care of the chronic-ventilated child need, including, but not limited to, tracheostomy care, emergency preparedness/CPR, home ventilator use, responding to monitors, and delivering respiratory medications. Each hospital should maintain up-to-date care guidelines and competency checklists for care of the child with chronic home invasive ventilation. Each family member must demonstrate adequate knowledge base and skills to care for the chronic ventilator-dependent child in the home. Transition of care conferences, such as when an extremely premature infant is ready for discharge home, must include all care providers who will be responsible for the long-term care of the child needing chronic home invasive ventilation. One recent example of this training process involved the development of a discharge planning care map for caregivers, which both streamlined the discharge planning process and decreased the length of hospital stay. ${ }^{4}$

Once the chronically ventilated child transitions to the home, the training and family support continues. The RT/DME company providers who make monthly inspections must reinforce the tracheostomy and ventilator education. If the child is in a foster home, the foster parents of a highly medically complex child are required to maintain a certain number of hours of continuing medical education.

\section{Q. How should a child requiring chronic home invasive ventilation be monitored when asleep?}

The guidelines recommend, "monitoring, especially when the child is asleep or unobserved, with a pulse oximeter rather than use of a cardiorespiratory monitor or sole use of the ventilator alarms."1 As we are taught in pediatric advanced life support, hypoxemia is an early indicator of airway obstruction or equipment malfunction, whereas bradycardia or apnea are late signs.

\section{Q. What have been the most important advances in home invasive ventilation in recent years?}

The most important advances in home invasive ventilation in recent years center around the advances in technology. The home ventilators we used just 20 years ago did not have continuous flow, which made it necessary to connect an Ambu bag in-line to simulate continuous flow. The older generation of the Pulmonetics LTV ${ }^{\circledR} 950$ (CareFusion, San Diego, CA, US) have an external PEEP valve in the expiratory circuit, making it difficult to maintain a constant PEEP. All ventilators we use today are continuous flow and have an integrated internal PEEP valve. A newer generation ventilator, the Trilogy ventilator (Philips, Amsterdam, Netherlands), has an automatic volume-adjusted pressure-support (AVAPS) mode, which maintains a more constant tidal volume by automatically adjusting the inspiratory positive airway pressure within certain preset parameters. The AVAPS mode may be helpful in the care of ventilator-dependent children with neuromuscular disease. The Hamilton C-3 ventilator (Hamilton Medical, Bonaduz, Switzerland) is another newer generation ventilator, which uses a mode of 
ventilation called adaptive support ventilation. Adaptive support ventilation is a mode of closed-loop controlled positive pressure ventilation, meaning the ventilator parameters are automatically adjusted based on the lung mechanics of the patient.
In addition to advances in ventilator technology, better monitoring equipment is available. Portable capnography units are available, which makes it easier to spot-check $\mathrm{pCO}_{2}$ and assess if the degree of ventilation is adequate. $\square$

1. Sterni LM, Collaco JM, Baker CD, et al. ATS Pediatric Chronic Home Ventilation Workgroup. An official American Thoracic Society clinical practice guideline: Pediatric chronic home invasive ventilation. Am J Respir Crit Care Med. 2016;193:e16-35

2. Amin R, MacLusky I, Zielinski D, et al. Pediatric home mechanical ventilation: A Canadian Thoracic Society clinical practice guideline executive summary. Canadian Journal of Respiratory, Critical Care, and Sleep Medicine. 2017;1:7-36.

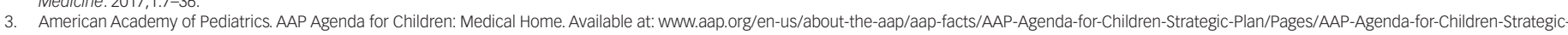
Plan-Medical-Home.aspx (accessed August 8, 2018)

4. Baker CD, Martin S, Thrasher J, et al. A standardized discharge process decreases length of stay for ventilator-dependent children. Pediatrics. 2016;137:e20150637. 